\title{
dspace.vutbr.cz
}

\section{Accurate Empirical Fractional-Order Electrical Models of Young and Old Dentines}

\author{
HERENCSÁR, N.; KARTCI, A.; CICEKOGLU, 0.
}

Proceedings of the 2020 42nd Annual International Conference of the IEEE Engineering in Medicine \& Biology Society (EMBC), pp. 2307-2310

elSBN: 978-1-7281-1990-8

ISSN: 2694-0604

DOI: https://doi.org/10.1109/EMBC44109.2020.9175916

Accepted manuscript

(C2020 IEEE. Personal use of this material is permitted. Permission from IEEE must be obtained for all other uses, in any current or future media, including reprinting/republishing this material for advertising or promotional purposes, creating new collective works, for resale or redistribution to servers or lists, or reuse of any copyrighted component of this work in other works. HERENCSÁR, N.; KARTCI, A.; CICEKOGLU, O., "Accurate Empirical Fractional-Order Electrical Models of Young and Old Dentines", 42nd Annual International Conference of the IEEE Engineering in Medicine \& Biology Society (EMBC), 2020. DOI: 10.1109/EMBC44109.2020.9175916. Final version is available at https://ieeexplore.ieee.org/document/9175916 


\title{
Accurate Empirical Fractional-Order Electrical Models of Young and Old Dentines
}

\author{
Norbert Herencsar ${ }^{1}$, Senior Member, IEEE, Aslihan Kartci ${ }^{1}$, Member, IEEE, \\ and Oguzhan Cicekoglu ${ }^{2}$, Member, IEEE
}

\begin{abstract}
Electrical impedance spectroscopy (EIS) is a fast, non-invasive, and safe technique for bioimpedance measurement. In dental research, EIS has been used to detect tooth cracks and caries with higher accuracy than visual and radiographic methods. Recently, a study has been reported on effect of age on impedance measurements for two age groups by employing EIS. The aim of that study was to demonstrate the usefulness of fractional calculus in equivalent circuit modeling. In proposed double dispersion Cole impedance (C-C) models, both resistance and pseudo-capacitance values were found to be significantly different for both age groups. However, in our study, the first time it was found out that proposed models' total pseudo-capacitance values of both young and old dentines can be reduced by $34 \%$ and $7.5 \%$, respectively, if recurrent electrical impedance model for $n=2$ bifurcations to be used. Secondly, new empirical fractional-order electrical models of human tooth using the optimized Valsa network with EIA standard compliant RC values are reported that provide better understanding of the structure of dentine from resistance and capacitance point of view.
\end{abstract}

\section{INTRODUCTION}

The electrical impedance of biological and biomedical tissues so-called bioimpedance is a complex quantity, which varies with the tissue's composition and the frequency of the electrical signal applied for impedance measurement. Therefore, its impedance is found as a frequency dependent complex function in a form $Z(j \omega)=\operatorname{Re}(Z)+j \cdot \operatorname{Im}(Z)$, where the real (Re - resistance $R(\Omega)$ ) and imaginary (Im - reactance $X(\Omega)$ ) parts of the complex impedance are calculated as $R=|Z| \cos \theta$ and $X=|Z| \sin \theta$, respectively. The electrical impedance spectroscopy (EIS) is a powerful technique that measures the variation of electrical impedance of an analyzed tissue by applying an electrical stimulus (a known noise signal, sinusoidal signal, or binary multifrequency signals of voltage or current) at different frequencies and then to observe the resulting current or voltage [1]. EIS is used in a broad range of applications. For instance, in dentistry, it has been used to detect cracks and caries in enamel and dentine, because early detection of dental caries poses a major challenge to modern dentistry. As it is known, dentine structure is considered as a complex hydrated

This article is based upon work from COST Action CA15225, a network supported by COST (European Cooperation in Science and Technology). Research described in this paper was financed by the Ministry of Education, Youth and Sports under grant LTC18022 of Inter-Cost program.

${ }^{1}$ Brno University of Technology, Department of Telecommunications, Technicka 3082/12, 61600 Brno, Czech Republic \{herencsn; kartci\}@feec.vutbr.cz. ${ }^{2}$ Bogazici University, Department of Electrical and Electronics Engineering, Bebek, Istanbul, 34342, Turkey cicekogleboun. edu.tr. composite and it constitutes the bulk of a human tooth and has unique ability to undergo structural changes [2]. It has been shown [3]-[8], in several in vitro and in vivo studies to be better than existing methods of caries diagnosis.

The interest in applications of the fractional calculus (FC) in modeling complex biomedical phenomena has increased significantly in recent decades, because best fitting accuracy is achieved between experimental and optimization results when constant phase elements (CPEs) are used in models [9]. Nowadays, Caputo definition of fractional-order differential operator describing CPE behavior is the most used, because the derivative of a constant is zero and the initial conditions are described in the same form as in the integer-order differential equations [10]. Caputo's derivative is described as ${ }_{0}^{C} D_{t}^{\alpha} f(t)=\frac{1}{\Gamma(n-\alpha)} \int_{0}^{t} \frac{f^{(n)}(\tau)}{(t-\tau)^{\alpha-n+1}} d \tau$, where $\Gamma(\cdot)$ is the gamma function and $n-1 \leq \alpha \leq n$. Applying the Laplace transform to Caputo's derivative yields $\mathcal{L}\left\{{ }_{0}^{C} D_{t}^{\alpha} f(t)\right\}=$ $s^{\alpha} F(s)-\sum_{k=0}^{n-1} s^{\alpha-k-1} f^{(k)}(0)$, where $f(0)$ is the initial condition. Therefore, the impedance of a fractional-order element is proportional to $s^{\alpha}$ and then it is possible to define the impedance expression for a capacitor, resistor, and inductor, respectively. One of the first attempts on applying FC in dentistry can be found in [11] when authors investigate the effect of dentine age (young and old) on impedance and equivalent double dispersion Cole impedance $(\mathrm{C}-\mathrm{C})$ model for each age group are proposed. However, up to date, no empirical teeth models have been reported that would provide better understanding of the structure of dentine from resistance and capacitance point of view. Therefore, in this paper, EIA standard compliant lumped parameter-based empirical models of teeth using recurrent electrical model for $n=2$ bifurcations are proposed that show minimum $99.988 \%$ fit accuracy with $34 \%$ or $7.5 \%$ less total pseudocapacitance in comparison with models reported in [11].

\section{MATERIALS AND METHODS}

\section{A. Dentine Samples Preparation, Data Collection, and Bioimpedance Model}

In brief, freshly extracted un-erupted human third molars were used to avoid the effect of attrition due to age. Two age groups were selected in the investigation; $20( \pm 1)$ and $50( \pm 1)$ years old and five dentine samples were collected from each age group. Bioimpedance measurements were carried out at $20{ }^{\circ} \mathrm{C}$ using a Solartron Analytical SI 1260 Impedance Gain-Phase Analyzer over the frequency range $10 \mathrm{mHz}$ to $10 \mathrm{MHz}$. More details of the sample preparation, 
TABLE I: Parameter Values for the Components of the Equivalent Circuit Models for Each Age Group.

\begin{tabular}{|c|c|c|c|c|c|c|c|}
\hline \multirow[t]{2}{*}{ Components } & \multirow[t]{2}{*}{ Elements } & \multicolumn{2}{|c|}{$\begin{array}{l}\text { Cole-Cole Model } \\
\text { Mean Values [11] }\end{array}$} & \multicolumn{2}{|c|}{$\begin{array}{l}\text { Proposed Model with } \\
\text { Random Values }\end{array}$} & \multicolumn{2}{|c|}{$\begin{array}{c}\text { Proposed Model with EIA } \\
\text { Standard Compliant RC Values }\end{array}$} \\
\hline & & Young Dentine & Old Dentine & Young Dentine & Old Dentine & Young Dentine & Old Dentine \\
\hline Saline solution & $R$-ss $(\Omega)$ & 71.5 & 72.1 & 71.5 & 72.1 & 71.5 & 72.3 \\
\hline \multirow{3}{*}{ Smear layer } & $\mathrm{CPE}_{\mathrm{T}-\mathrm{S}}\left(\mu F \cdot s^{-0.5}\right)$ & 23.8 & 14.6 & 15.64 & 13.52 & 15.6 & 13.5 \\
\hline & CPEP-s (-) & \multicolumn{6}{|c|}{0.5} \\
\hline & $R$-s $(\Omega)$ & 244 & 128.1 & 564.3 & 149.38 & 562 & 150 \\
\hline \multirow{3}{*}{ Dentine } & $\mathrm{CPE}_{\mathrm{T}}-\mathrm{d}\left(\mu F \cdot s^{-0.5}\right)$ & 45.6 & 182.8 & 30.23 & 169.34 & 30.1 & 169 \\
\hline & $\mathrm{CPE}_{\mathrm{P}-\mathrm{d}(-)}$ & \multicolumn{6}{|c|}{0.5} \\
\hline & $R-\mathrm{d}(\mathrm{k} \Omega)$ & 43.1 & 60.9 & 42.78 & 60.88 & 43 & 60.4 \\
\hline \multicolumn{2}{|c|}{ Total pseudo-capacitance $\left(\mu F \cdot s^{-0.5}\right)$} & 69.4 & 197.4 & 45.87 & 182.86 & 45.7 & 182.5 \\
\hline \multicolumn{2}{|c|}{ Total resistance $(\mathrm{k} \Omega)$} & 43.42 & 61.1 & 43.42 & 61.1 & 43.63 & 60.62 \\
\hline
\end{tabular}

sample holder, physiological saline solution, and impedance of a control electrical are given in [11]. It was found out that C-C model using Warburg impedances (order of CPEs is 0.5) provides the best fit accuracy. The electrical component values of proposed circuit model depicted in Fig. 1(a) for each age group is shown in Table I. As it can be observed, the smear layer over the dentine surface and dentine itself have their own resistance (respectively $R$ $\mathrm{s}, R-\mathrm{d})$ and pseudo-capacitance $\left(\mathrm{CPE}_{T}{ }^{-\mathrm{S}}, \mathrm{CPE}_{T}-\mathrm{d}\right)$, while the saline solution resistance $R$-ss only. However, proposed models' [11] total pseudo-capacitance values of both age groups can be significantly reduced, as shown below.

\section{B. Statistical Analysis}

Standard and widely used statistical analyses [1] such as relative error of magnitude of CPEs, phase angle error of CPEs, relative error of real and imaginary parts of the complex bioimpedances, and the determination coefficients $\left(\mathrm{R}_{\mathrm{R}}^{2}, \mathrm{R}_{\mathrm{X}}^{2}\right)$ of the fitted models with random values and via EIA standard compliant RC values and standard deviation (Std. Dev.) were calculated in the next section for estimating the accuracy of the proposed models.

\section{RESULTS AND DISCUSSION}

\section{A. Proposed Empirical Fractional-Order Electrical Model of Teeth with Reduced CPEs}

The recurrent electrical impedance model for $n=2$ bifurcations is shown in Fig. 1(b) [10]. This model again consists of three resistors and two CPEs, hence it ensures modeling of the resistance and pseudo-capacitance of smear layer and dentine as well as the saline solution resistance. Assuming usage of Warburg impedances (equal order labeled

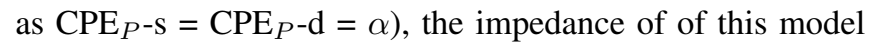
is described by:

$$
\begin{aligned}
& Z(s)=R-s s+ \\
& +\frac{1}{s^{\alpha} \cdot C P E_{T^{-}}+\frac{1}{R-s+\frac{1}{s^{\alpha} \cdot C P E_{T^{-}} d+\frac{1}{R-d}}}}
\end{aligned}
$$

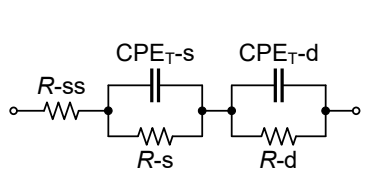

(a)

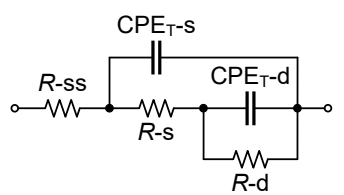

(b)
Fig. 1: (a) Double dispersion Cole impedance model, (b) recurrent electrical impedance model for $n=2$ bifurcations.

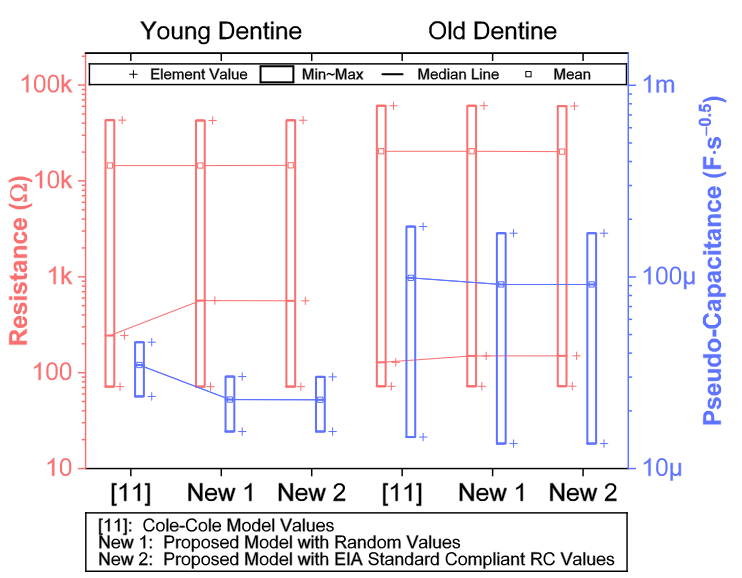

Fig. 2: Comparison of resistance and pseudo-capacitance values in [11] and proposed circuit models of teeth.

where $s=j \omega$. The complex impedance of (1) can be expressed by applying theory [12], but here it is not given due to page constraints. The recurrent electrical impedance model parameters were obtained by applying [12] and numerically re-analyzing the complex impedance of C-C model for each age group. The component values for both random values and via EIA standard compliant RC values are listed in Table I. Here it is worth noting that while the total resistance remained nearly the same, the total pseudo-capacitance are reduced by $34 \%$ and $7.5 \%$ for young and old dentines, respectively, in comparison with models reported in [11]. This is also evident from comparison of resistance and pseudo-capacitance values shown in Fig. 2. 
TABLE II: Standard EIA Compliant RC Values Used in Proposed CPEs of Orders 0.5 via Valsa Network and Error Analysis.

\begin{tabular}{|c|c|c|c|c|}
\hline \multirow{4}{*}{ Elements } & \multicolumn{4}{|c|}{ Valsa RC Network } \\
\hline & \multicolumn{2}{|c|}{ Young Dentine } & \multicolumn{2}{|c|}{ Old Dentine } \\
\hline & $\mathbf{C P E} \mathbf{E}_{T}-\mathbf{s}$ & $\mathbf{C P E}_{T}-\mathbf{d}$ & $\mathbf{C P E}_{T}-\mathbf{s}$ & $\mathrm{CPE}_{T}-\mathrm{d}$ \\
\hline & $15.6 \mu F \cdot s^{-0.5}$ & $30.1 \mu F \cdot s^{-0.5}$ & $13.5 \mu F \cdot s^{-0.5}$ & $169 \mu F \cdot s^{-0.5}$ \\
\hline$C_{0}(\mathrm{~F}) / R_{0}(\Omega)$ & $680 \mathrm{p} / 787 \mathrm{k}$ & $10.2 \mathrm{p} / 383 \mathrm{k}$ & $562 \mathrm{p} / 887 \mathrm{k}$ & $6.8 \mathrm{n} / 73.2 \mathrm{k}$ \\
\hline$C_{1}(\mathrm{~F}) / R_{1}(\Omega)$ & $2.61 \mathrm{n} / 38.3$ & $1.8 \mu / 6.34 \mathrm{k}$ & $12.1 \mathrm{n} / 232$ & $66.5 \mathrm{n} / 7.68$ \\
\hline$C_{2}(\mathrm{~F}) / R_{2}(\Omega)$ & $6.2 \mathrm{n} / 86.6$ & $3.74 \mathrm{n} / 12$ & $29.4 \mathrm{n} / 536$ & $11.8 \mu / 1.37 \mathrm{k}$ \\
\hline$C_{3}(\mathrm{~F}) / R_{3}(\Omega)$ & $30 \mathrm{n} / 470$ & $2.43 \mathrm{n} / 1.8$ & $66.5 \mathrm{n} / 1.27 \mathrm{k}$ & $4.99 \mu / 590$ \\
\hline$C_{4}(\mathrm{~F}) / R_{4}(\Omega)$ & $13.7 \mathrm{n} / 205$ & $8.66 \mathrm{n} / 30.9$ & $158 \mathrm{n} / 2.94 \mathrm{k}$ & $28 \mathrm{n} / 3.3$ \\
\hline$C_{5}(\mathrm{~F}) / R_{5}(\Omega)$ & $909 \mathrm{n} / 13.3 \mathrm{k}$ & $21.5 \mathrm{n} / 73.2$ & $365 \mathrm{n} / 6.98 \mathrm{k}$ & $13.7 \mathrm{n} / 1.1$ \\
\hline$C_{6}(\mathrm{~F}) / R_{6}(\Omega)$ & $42.2 \mu / 374 \mathrm{k}$ & $4.32 \mu / 15.4 \mathrm{k}$ & $35.7 \mu / 442 \mathrm{k}$ & $66.5 \mu / 7.68 \mathrm{k}$ \\
\hline$C_{7}(\mathrm{~F}) / R_{7}(\Omega)$ & $1.33 \mathrm{n} / 12.7$ & $52.3 \mathrm{n} / 180$ & $5.23 \mathrm{n} / 100$ & $374 \mathrm{n} / 43.2$ \\
\hline$C_{8}(\mathrm{~F}) / R_{8}(\Omega)$ & $178 \mathrm{n} / 2.4 \mathrm{k}$ & $309 \mathrm{n} / 1.07 \mathrm{k}$ & $887 \mathrm{n} / 16 \mathrm{k}$ & $909 \mathrm{n} / 102$ \\
\hline$C_{9}(\mathrm{~F}) / R_{9}(\Omega)$ & $14 \mu / 178 \mathrm{k}$ & $76.8 \mu / 187 \mathrm{k}$ & $2.32 \mathrm{n} / 41.2$ & $28 \mu / 3.24 \mathrm{k}$ \\
\hline$C_{10}(\mathrm{~F}) / R_{10}(\Omega)$ & $2.26 \mu / 29.4 \mathrm{k}$ & $25.5 \mu / 88.7 \mathrm{k}$ & $2.05 \mu / 38.3 \mathrm{k}$ & $158 \mathrm{n} / 18.2$ \\
\hline$C_{11}(\mathrm{~F}) / R_{11}(\Omega)$ & $75 \mathrm{n} / 1.02 \mathrm{k}$ & $127 \mathrm{n} / 442$ & $1.1 \mathrm{n} / 14$ & $2.15 \mu / 249$ \\
\hline$C_{12}(\mathrm{~F}) / R_{12}(\Omega)$ & $402 \mathrm{n} / 5.9 \mathrm{k}$ & $10.5 \mu / 36.5 \mathrm{k}$ & $12 \mu / 215 \mathrm{k}$ & $464 \mu / 36.5 \mathrm{k}$ \\
\hline$C_{13}(\mathrm{~F}) / R_{13}(\Omega)$ & $5.76 \mu / 69.8 \mathrm{k}$ & $750 \mathrm{n} / 2.61 \mathrm{k}$ & $4.99 \mu / 88.7 \mathrm{k}$ & $154 \mu / 18.2 \mathrm{k}$ \\
\hline \multicolumn{5}{|c|}{ |Relative magnitude error $|(\%) /|$ Phase angle error $\mid$ (Deg.) } \\
\hline Max & $1.15 / 0.62$ & $1.19 / 0.56$ & $1.08 / 0.61$ & $1.19 / 0.53$ \\
\hline Mean & $0.47 / 0.25$ & $0.49 / 0.28$ & $0.42 / 0.24$ & $0.48 / 0.24$ \\
\hline Median & $0.42 / 0.24$ & $0.47 / 0.3$ & $0.38 / 0.24$ & $0.46 / 0.24$ \\
\hline Std. Dev. & $0.3 / 0.15$ & $0.29 / 0.14$ & $0.27 / 0.14$ & $0.31 / 0.13$ \\
\hline
\end{tabular}

\section{B. Proposed Empirical Models of CPEs via Valsa Network}

For better understanding of the structure of dentine from resistance and capacitance point of view, the CPEs in Fig. 1(b) fitted to EIA standard compliant values were realized via Valsa RC network [13]. CPEs were optimized using approach [14] powered by genetic algorithm, which based on defined fitness function provides a phase optimization in the desired bandwidth $(10 \mathrm{mHz}$ to $10 \mathrm{MHz})$ with determined branch number (13 in this work) without any complex mathematical analysis. Table II lists the standard EIA compliant RC values used in proposed CPEs with desired pseudo-capacitances and orders via Valsa network. Example of phase variation of proposed CPEs for the young dentine and ideal and simulated phase and magnitude responses vs. frequency as an inset are shown in Fig. 3. The fitted equations using power and linear regressions for the magnitudes and for the phases, respectively, are given inside figure. Distribution of resistance and capacitance values for both age groups are depicted in Fig. 4. From the obtained results it is evident that the maximum relative magnitude errors for young and old dentine are $\pm 1.19 \%$ with maximum phase angle error $\pm 0.62^{\circ}$ and $\pm 0.61^{\circ}$, respectively, in defined frequency range.

\section{Comparison of Bioimpedance Models}

For biological and biomedical tissues, the relationship between $R$ and $X$ of the complex impedance can be described

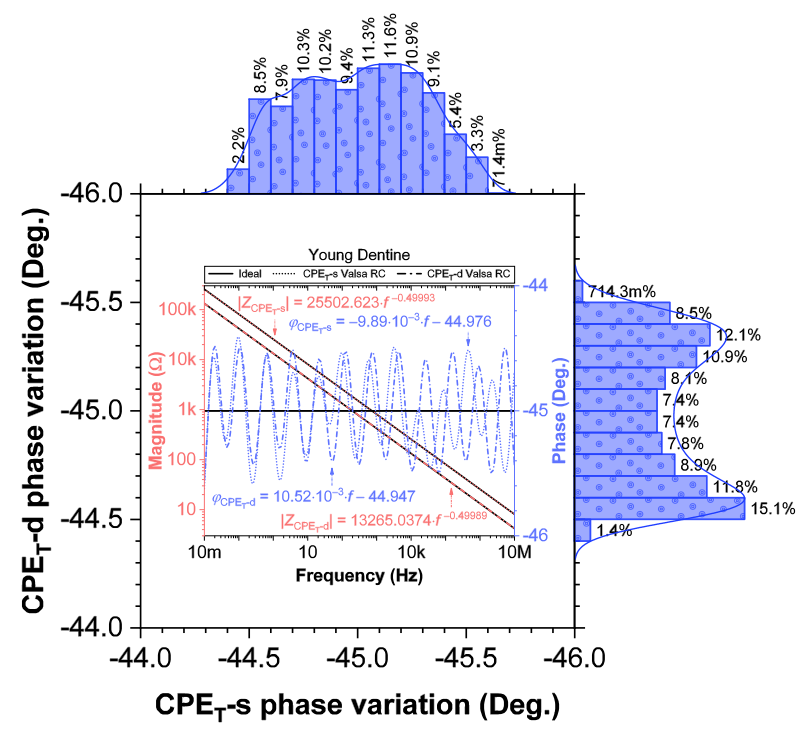

Fig. 3: Example of phase variation of proposed CPEs of orders 0.5 via Valsa RC network with phase and magnitude responses vs. frequency as an inset for the young dentine.

with a circular arc in the Nyquist plot. These plots of simulated [11] and proposed fitting circuit models of teeth are shown in Fig. 5. Plotted zooms as insets for young 


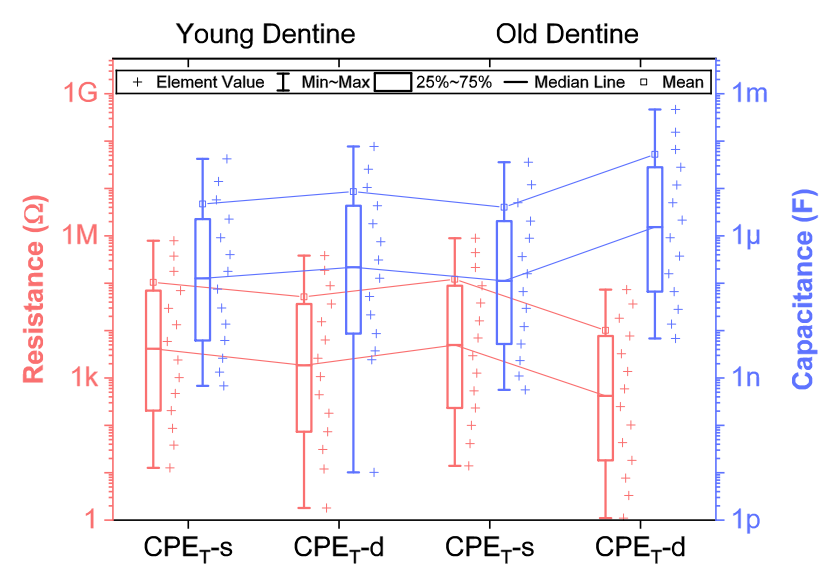

Fig. 4: Distribution of resistance and capacitance values in Valsa RC network for realizing CPEs of orders 0.5.

and older dentine show similar appearances for both age groups. Statistical analysis results are given in Tab. III. From the obtained results it is evident that the maximum relative errors of $R$ and $X$ of the complex impedance varies from $0.9 \%$ to $1.82 \%$, respectively, over frequency range form 10 $\mathrm{mHz}$ to $10 \mathrm{MHz}$. Note that the corresponding coefficients of determination of $\mathrm{R}_{\mathrm{R}, \mathrm{X}}^{2}$ between the initial C-C model and proposed electrical equivalent circuit models for fitting show $99.988 \%$ to $100 \%$ fit accuracy with low standard deviation.

\section{CONCLUSIONS}

Fractional-order bioimpedance circuit models provide a better fit accuracy for impedance data of any tissues over their integer-order counterparts. These models, while lacking in commercial unavailability of CPEs, empirical equivalents employing EIA standard compliant RC values providing an explanation of their structures, are still very useful in practical applications.

\section{REFERENCES}

[1] F. Simini and P. Bertemes-Filho, eds., Bioimpedance in Biomedical Applications and Research. Springer, Cham, 2018.

[2] G. W. Marshall, "Dentin: Microstructure and characterization," Quintessence International, vol. 24, no. 9, pp. 606-617, 1993.

[3] C. Longbottom, M.-C. D. N. J. Huysmans, N. B. Pitts, P. Los, and P. G. Bruce, "Detection of dental decay and its extent using a.c. impedence spectroscopy," Nature Medicine, vol. 2, no. 2, pp. 235-237, 1996.

[4] C. Longbottom and M.-C. D. N. J. Huysmans, "Electrical measurements for use in caries clinical trials," Journal of Dental Research, vol. 83, no. Spec Iss C, pp. C76-C79, 2004.

[5] I. A. Pretty, "Caries detection and diagnosis: Novel technologies," Journal of Dentistry, vol. 34, no. 10, pp. 727-739, 2006.

[6] B. Rivas, P. M. Botta, P. Varela, B. Martín, A. Fondado, and J. Rivas, "In vitro electrical impedance spectroscopy of human dentine: The effect of restorative materials," Bioelectromagnetics, vol. 29, no. 3, pp. 163-168, 2008.

[7] J.-H. Huang, S.-C. Yen, and C.-P. Lin, "Impedance characteristics of mimic human tooth root canal and its equivalent circuit model," Journal of The Electrochemical Society, vol. 155, no. 5, pp. P51-P56, 2008.

[8] A. P. Morais, A. V. Pino, and M. N. Souza, "Detection of questionable occlusal carious lesions using an electrical bioimpedance method with fractional electrical model," Review of Scientific Instruments, vol. 87, no. 8, pp. 084305-1-084305-6, 2016.

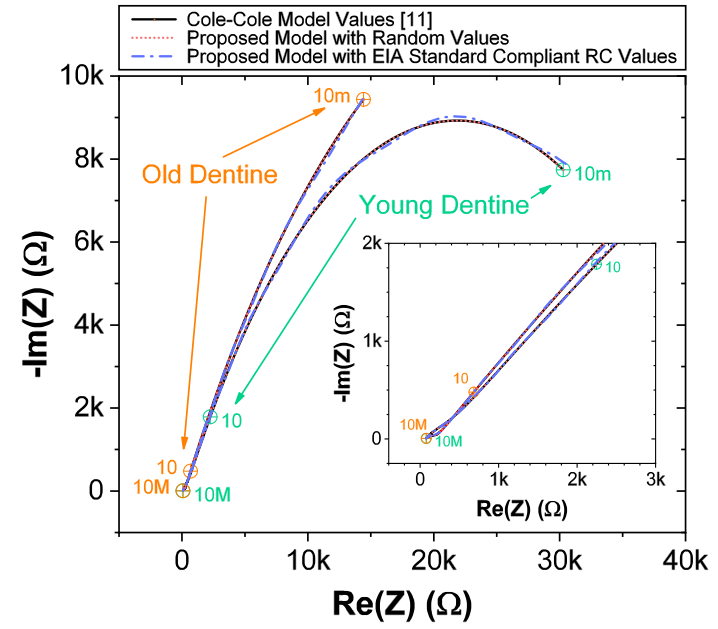

Fig. 5: Nyquist plots of simulated [11] and proposed models of young and old dentine with zoom at high frequency region as an inset. Selected frequencies are highlighted.

TABLE III: Comparison of Results of Proposed Models Fitted to Data of [11] and Indexes of Fit Accuracy.

\begin{tabular}{|c|c|c|c|c|}
\hline \multirow{2}{*}{$\begin{array}{c}\text { Evaluation } \\
\text { Criteria }\end{array}$} & \multicolumn{2}{|c|}{$\begin{array}{l}\text { Proposed Model } \\
\text { with Random } \\
\text { Values }\end{array}$} & \multicolumn{2}{|c|}{$\begin{array}{c}\text { Proposed Model } \\
\text { with EIA Standard } \\
\text { Compliant RC Values }\end{array}$} \\
\hline & $\begin{array}{l}\text { Young } \\
\text { Dentine }\end{array}$ & $\begin{array}{c}\text { Old } \\
\text { Dentine }\end{array}$ & $\begin{array}{l}\text { Young } \\
\text { Dentine }\end{array}$ & $\begin{array}{c}\text { Old } \\
\text { Dentine }\end{array}$ \\
\hline \multicolumn{5}{|c|}{$\mid$ Relative $\operatorname{Re}(Z)$ error $|(\%) /|$ Relative $-\operatorname{Im}(Z)$ error $\mid(\%)$} \\
\hline Max & \multirow{4}{*}{$0 / 0$} & \multirow{4}{*}{$0 / 0$} & $1.05 / 1.82$ & $0.9 / 1.58$ \\
\hline Mean & & & $0.33 / 0.62$ & $0.35 / 0.61$ \\
\hline Median & & & $0.27 / 0.58$ & $0.31 / 0.59$ \\
\hline Std. Dev. & & & $0.27 / 0.39$ & $0.21 / 0.4$ \\
\hline$\overline{\mathrm{R}_{\mathrm{R}}^{2}(\%)}$ & \multirow{2}{*}{100} & \multirow{2}{*}{100} & 99.997 & 99.997 \\
\hline $\mathrm{R}_{\mathrm{X}}^{2}(\%)$ & & & 99.989 & 99.988 \\
\hline Std. Dev. $(\Omega)$ & \multicolumn{2}{|c|}{0} & 52.46 & 29.03 \\
\hline
\end{tabular}

[9] C. Ionescu, A. Lopes, D. Copot, J. A. T. Machado, and J. H. T. Bates, "The role of fractional calculus in modeling biological phenomena: A review," Communications in Nonlinear Science and Numerical Simulation, vol. 51, pp. 141-159, 2017.

[10] J.-J. Cabrera-López and J. Velasco-Medina, "Structured approach and impedance spectroscopy microsystem for fractional-order electrical characterization of vegetable tissues," IEEE Transactions on Instrumentation and Measurement, vol. 69, pp. 469-478, Feb. 2020.

[11] A. H. Eldarrat, D. J. Wood, G. M. Kale, and A. S. High, "Age-related changes in ac-impedance spectroscopy studies of normal human dentine," Journal of Materials Science: Materials in Medicine, vol. 18 , no. 6, pp. 1203-1210, 2007.

[12] A. Kartci, A. Agambayev, N. Herencsar, and K. N. Salama, "Series-, parallel-, and inter-connection of solid-state arbitrary fractional-order capacitors: Theoretical study and experimental verification," IEEE Access, vol. 6, pp. 10933-10943, 2018.

[13] J. Valsa and J. Vlach, "RC models of a constant phase element," International Journal of Circuit Theory and Applications, vol. 41, no. 1, pp. 59-67, 2013.

[14] A. Kartci, A. Agambayev, M. Farhat, N. Herencsar, L. Brancik, H. Bagci, and K. N. Salama, "Synthesis and optimization of fractionalorder elements using a genetic algorithm," IEEE Access, vol. 7, pp. 80233-80246, 2019. 